\title{
Duboisia leichhardtii (F.Muell.) Extracts Inhibit The Growth of Bacterial Triggers of Selected Autoimmune Inflammatory Diseases
}

\author{
Ian Edwin Cock ${ }^{1,2}$
}

\section{Ian Edwin Cock}

'School of Natural Sciences, Griffith University, 170 Kessels Rd, Nathan, Brisbane, Queensland 4111, AUSTRALIA. ${ }^{2}$ Environmental Futures Research Institute, Griffith University, 170 Kessels Rd, Nathan, Brisbane, Queensland 4111, Australia.

\section{Correspondence}

Ian Edwin Cock, School of Natural Sciences, Griffith University, 170 Kessels Road, Nathan, Brisbane, Queensland 4111, AUSTRALIA.

Tel.: + 61737357637 ;

fax: +61737355282

Email: I.Cock@griffith.edu.au

$$
\text { (I. E. Cock) }
$$

DOI : 10.5530/pj.2016.6.5

\section{Article Available online}

http://www.phcogj.com/v8/i6

\section{Copyright}

(C) 2016 Phcog.Net. This is an openaccess article distributed under the terms of the Creative Commons Attribution 4.0 International license.

\begin{abstract}
Introduction: Duboisia leichhardtii F.Muell. is a medium to large tree which is native to subtropical regions of eastern Australia. Duboisia spp. contain a number of psychoactive tropane and pyrrolidine alkaloids with reported antibacterial activity. Despite this, D. leichhardtii leaf extracts have not been rigorously examined for growth inhibitory properties against many bacteria, including the bacterial triggers of autoimmune inflammatory diseases. Methods: The antimicrobial activity of $D$. leichhardtii leaf solvent extracts was investigated by disc diffusion and growth time course assays against a panel of bacterial triggers of autoimmune diseases. The growth inhibitory activity was further quantified by MIC determination and growth time course assays. Toxicity was determined using the Artemia franciscana nauplii bioassay. Results: Methanolic and aqueous $D$. leichhardtii leaf solvent extracts were potent inhibitors of the bacterial triggers of rheumatoid arthritis and ankylosing spondylitis. The methanolic extract displayed the most potent bacterial growth inhibitory activity. It was particularly potent against $P$. mirabilis (MICs of 85 and $116 \mu \mathrm{g} / \mathrm{mL}$ against reference and clinical strains respectively) and $P$. vulgaris (MIC of $187 \mu \mathrm{g} / \mathrm{mL}$ ). The methanolic extract was also a good inhibitor of $K$. pneumoniae growth (MICs of 143 and $118 \mu \mathrm{g} / \mathrm{mL}$ against reference and clinical strains respectively). The aqueous and ethyl acetate extracts were also potent bacterial growth inhibitors, albeit with higher MIC values. The antibacterial activity of the methanolic and aqueous $D$. leichhardtii leaf extracts were further investigated by growth time course assays which showed significant growth inhibition in cultures of $P$. mirabilis and $K$. pneumoniae within $1 \mathrm{~h}$ of exposure. All extracts were determined to be nontoxic in the Artemia franciscana nauplii bioassay, indicating their safety for use in preventing these autoimmune inflammatory diseases. Conclusions: The lack of toxicity of the D. leichhardtii leaf extracts and their growth inhibitory bioactivity against the bacterial triggers of rheumatoid arthritis and ankylosing spondylitis indicate their potential in the development of new therapies targeting the onset of these diseases.
\end{abstract}

Key words: Solanaceae, Corkwood, Rheumatoid Arthritis, Ankylosing Spondylitis, Multiple Sclerosis, Rheumatic Heart Disease, Scopolamine, Hyoscyamine.

\section{INTRODUCTION}

Autoimmune inflammatory disorders (e.g. rheumatoid arthritis, ankylosing spondylitis, multiple sclerosis and rheumatic heart disease) are a group of debilitating conditions which may afflict genetically susceptible individuals. There are no cures for any of these diseases. Instead, current treatment strategies aim to alleviate the symptoms (particularly pain, swelling and inflammation) with analgesics and antiinflammatory agents, and/or to modify the disease process through the use of disease modifying drugs. None of these treatments is ideal as prolonged drug therapy is often accompanied by unwanted side effects and toxicity. ${ }^{1}$ There is a need to develop safer, more effective treatments for these conditions which not only alleviate the symptoms, but may also cure or prevent the disease. A greater understanding of the onset and progression of these disorders should greatly assist in more relevant drug discovery and development.

Autoimmune disorders are triggered in susceptible individuals by specific microbial infections. Recent sero-typing studies have identified the microbial triggers of some of these conditions. ${ }^{2-7}$ A microbial trigger of rheumatoid arthritis has been identified as Proteus mirabilis. ${ }^{2-4}$ Similarly, Klebsiella pneumoniae has been shown to initiate ankylosing spondylitis. ${ }^{2,5-7}$ Acinetobacter baylyi and Pseudomonas aeruginosa have been linked with the onset of multiple sclerosis. ${ }^{8}$ Borrelia burgdorferi is linked with Lyme disease. ${ }^{9}$ Streptococcus pyogenes can induce rheumatic heart disease in genetically susceptible individuals. ${ }^{10,11}$ Members of the Enterobacteraceae family are associated with Graves' disease and Kawasaki syndrome and Mycoplasma pneumoniae is associated with several demyelinating diseases. ${ }^{12}$ The development of 
antibiotic agents targeted at the specific bacterial triggers of autoimmune inflammatory disorders would enable afflicted individuals to target these microbes and thus prevent the onset of the disease and reduce the severity of the symptoms once the disease has progressed.

A re-examination of traditional medicines for the treatment of autoimmune inflammatory conditions is an attractive prospect as the antiseptic and anti-inflammatory qualities of medicinal plants have been long recognised. Furthermore, there has recently been a revival of interest in herbal medications due to a perception that there is a lower incidence of adverse reactions to plant preparations compared to synthetic pharmaceuticals. Duboisia leichhardtii (F.Muell.) (synonymn: Anthocercis leichardtii (F.Muell.); commonly known as corkwood, poisoness corkwood, yellow basswood, Queensland Duboisia) is a medium to large tree of the family Solonaceae. It grows in subtropical regions of eastern Australia, particularly in South East Queensland and Northern New South Wales. The tree grows to $12 \mathrm{~m}$ tall and has thick, corky bark from which its common name is derived. The leaves are narrowly elliptical (Figure 1a; 5-10 cm long). White flowers (Figure $1 \mathrm{~b}$ ) are produced and develop into globose berries ( $5 \mathrm{~mm}$ in diameter). The use of several Duboisia spp. in traditional Australian bush medicine to treat gastrointestinal maladies and eye disease has been documented ${ }^{13-15}$.Furthermore, the leaves, flowers and twigs of several Duboisia spp. may have been used by the first Australians as sedatives and hyptnotics, ${ }^{13-15}$ although conclusive documentation is lacking.

The phytochemistry of $D$. leichhardtii has not been extensively reported. Indeed, most of the interest in Duboisia spp. has focussed on the tropane alkaloids scopolamine (Figure 1e), hyoscyamine (Figure 1c) and norhyoscyamine (Figure 1d), and the pyrrolidine alkaloids (Figure 1f) nicotine and nornicotine (Figure $1 \mathrm{~g}$ ). These compounds are common to all Duboisia spp. (although the relative levels differ between species/locations). ${ }^{15}$ these alkaloids have attracted interest as all have potent psychoactive properties via acetylcholine receptor antagonism. Thus, they are indicated as sedatives and hypnotics (or stimulants at low doses). ${ }^{15}$ However, these alkaloids are also toxic, so should be used with caution. Interestingly, potent antibacterial activity has also been reported for some of these compounds. Scopolamine is a potent inhibitor of the growth of multiple bacteria, with MIC values as low as $2 \mu \mathrm{g} / \mathrm{mL}$ against some bacteria. ${ }^{16}$ Similarly, nicotine inhibits the growth of E. coli, P. aeruginosa and S. faecalis. ${ }^{17}$ However, MIC values were not determined in that study, making it impossible to compare the efficacy with other studies. Despite these previous studies, examination of the antibacterial properties and phytochemistry of $D$. leichhardtii leaves is rudimentary. The current report was undertaken to screen $D$. leichhardtii leaf extracts for growth inhibitory properties against bacterial triggers of selected autoimmune inflammatory diseases.

\section{MATERIALS AND METHODS.}

\section{Plant collection and extraction.}

Duboisia leichhardtii (F.Muell.) leaves were obtained from Philip Cameron, senior botanical officer, Mt Cootha Botanical Gardens, Brisbane, Australia. The leaf samples were dried in a Sunbeam food dehydrator and stored at $-30{ }^{\circ} \mathrm{C}$. Prior to use, the dried leaves were freshly ground to a coarse powder and $1 \mathrm{~g}$ quantities were weighed into separate tubes. A volume of $50 \mathrm{~mL}$ methanol, sterile deionised water, ethyl acetate, chloroform or hexane was added to individual tubes and extracted for 24 hours at $4{ }^{\circ} \mathrm{C}$ with gentle shaking. All solvents were obtained from Ajax, Australia and were AR grade. The extracts were filtered through filter paper (Whatman No. 54) under vacuum, followed by drying by rotary evaporation in an Eppendorf concentrator 5301. The resultant pellets were dissolved in $10 \mathrm{~mL}$ sterile deionised water (containing $1 \% \mathrm{DMSO}$ ). The extracts were passed through $0.22 \mu \mathrm{m}$ filter (Sarstedt) and stored at $4{ }^{\circ} \mathrm{C}$ until use.

\section{Qualitative phytochemical studies.}

Phytochemical analysis of the D. leichhardtii leaf extracts for the presence of saponins, phenolic compounds, flavonoids, phytosteroids, triterpenoids, cardiac glycosides, anthraquinones, tannins and alkaloids was conducted by standard assays. ${ }^{18-20}$

\section{Antibacterial screening}

\section{Test micro organisms.}

All media was supplied by Oxoid Ltd. Australia. Reference strains of Acinitobacter baylyi (ATCC33304), Klebsiella pneumoniae (ATCC31488), Proteus mirabilis (ATCC21721), Proteus vulgaris (ATCC21719), and Pseudomonas aeruginosa (ATCC39324) were purchased from American Tissue Culture Collection, USA. All clinical microbial strains were obtained from the School of Natural Sciences teaching laboratory, Griffith University. All stock cultures were subcultured and maintained in nutrient broth at $4{ }^{\circ} \mathrm{C}$.

\section{Evaluation of antimicrobial activity.}

Antimicrobial activity of the D. leichhardtii extracts was determined using a modified disc diffusion assay. ${ }^{21-23}$ briefly, $100 \mu \mathrm{L}$ of each bacterial culture was grown in $10 \mathrm{~mL}$ of fresh nutrient broth until they reached a count of $\sim 10^{8}$ cells $/ \mathrm{mL}$. A volume of $100 \mu \mathrm{L}$ of the bacterial suspension was spread onto nutrient agar plates and the extracts were tested for antibacterial activity using $5 \mathrm{~mm}$ sterilised filter paper discs. Discs were infused with $10 \mu \mathrm{L}$ of the plant extracts, allowed to dry and placed onto the inoculated plates. The plates were allowed to stand at $4{ }^{\circ} \mathrm{C}$ for $2 \mathrm{~h}$ before incubation at $30^{\circ} \mathrm{C}$ for $24 \mathrm{~h}$. The diameters of the inhibition zones were measured to the closest whole millimetre. Each assay was performed in at least triplicate. Mean values $( \pm$ SEM $)$ are reported in this study. Standard discs of ampicillin $(10 \mu \mathrm{g})$ were obtained from Oxoid, Australia and were used as positive controls to compare antibacterial activity. Filter discs infused with $10 \mu \mathrm{L}$ of distilled water were used as a negative control.

\section{Minimum inhibitory concentration (MIC) determination.}

The minimum inhibitory concentration (MIC) of each extract against susceptible bacteria was determined as previously described. ${ }^{24-25}$ Briefly, the $D$. leichhardtii leaf extracts were diluted in deionised water and tested across a range of concentrations. Discs were infused with $10 \mu \mathrm{L}$ of the test dilutions, allowed to dry and placed onto inoculated plates. The assay was completed as outlined above and graphs of the zone of inhibition versus concentration were plotted for each extract. Linear regression was used to determine the MIC values of each extract.

\section{Bacterial growth time course assay.}

Bacterial growth time course studies were performed as previously described. ${ }^{26}$ Briefly, $3 \mathrm{~mL}$ of Proteus mirabilis (ATCC21721) and Klebsiella pneumoniae (ATCC31488) in nutrient broth were individually added to $27 \mathrm{~mL}$ nutrient broth containing $3 \mathrm{~mL}$ of $10 \mathrm{mg} / \mathrm{mL}$ methanolic or aqueous plant extract to give a final concentration of $1000 \mu \mathrm{g} / \mathrm{mL}$ in the assay. The tubes were incubated at $30{ }^{\circ} \mathrm{C}$ with gentle shaking. The optical density was measured hourly at $550 \mathrm{~nm}$ for a $6 \mathrm{~h}$ incubation period. Control tubes were incubated under the same conditions but without the extract. All assays were performed in triplicate.

\section{Toxicity screening}

\section{Reference toxin for toxicity screening.}

Potassium dichromate $\left(\mathrm{K}_{2} \mathrm{Cr}_{2} \mathrm{O}_{7}\right)$ (AR grade, Chem-Supply, Australia) was prepared as a $4 \mathrm{mg} / \mathrm{mL}$ solution in distilled water and was serially diluted in artificial seawater for use in the Artemia franciscana nauplii bioassay. 


\section{Artemia franciscana nauplii toxicity screening.}

Toxicity was tested using an adapted Artemia franciscana nauplii lethality assay. ${ }^{27-29}$ Briefly, $400 \mu \mathrm{L}$ of seawater containing approximately 55 (mean $55.2, \mathrm{n}=125, \mathrm{SD} 14.5$ ) A. franciscana nauplii were added to wells of a 48 well plate and immediately used for bioassay. A volume of $400 \mu \mathrm{L}$ of diluted plant extracts or the reference toxin were transferred to the wells and incubated at $25 \pm 1^{\circ} \mathrm{C}$ under artificial light (1000 Lux). A $400 \mu \mathrm{L}$ seawater negative control was run in triplicate for each plate. All treatments were performed in at least triplicate. The wells were checked at regular intervals and the number of dead counted. The nauplii were considered dead if no movement of the appendages was detected within 10 seconds. After $24 \mathrm{~h}$, all nauplii were sacrificed and counted to determine the total $\%$ mortality per well. The $\mathrm{LC}_{50}$ with $95 \%$ confidence limits for each treatment was determined using probit analysis.

\section{Statistical analysis.}

Data are expressed as the mean \pm SEM of at least three independent experiments. One way ANOVA was used to calculate statistical significance between control and treated groups with a $P$ value $<0.01$ considered to be statistically significant.

\section{RESULTS.}

\section{Liquid extraction yields and qualitative phytochemical screening.}

Extraction of $1 \mathrm{~g}$ of dried and powdered $D$. leichhardtii leaves with solvents of varying polarity yielded dried extracts ranging from $137 \mathrm{mg}$ (hexane extract) to $253 \mathrm{mg}$ (methanol extract) (Table 1). The aqueous $(225 \mathrm{mg}$ ) and chloroform extracts $(186 \mathrm{mg}$ ) also yielded relatively high levels of extracted material. The dried extracts were resuspended in $10 \mathrm{~mL}$ of deionised water (containing $1 \%$ DMSO), resulting in the extract concentrations shown in Table 1. Qualitative phytochemical studies showed that the higher polarity methanol and water solvents extracted the greatest diversity and highest levels of phytochemicals. Both contained high levels of phenolics and flavonoids, as well as moderate levels of alkaloids and tannins. The ethyl acetate extract contained similar phytochemical classes, albeit generally at substantially lower levels. Interestingly, despite extracting relatively large amounts of material, the chloroform and hexane extracts were generally devoid of all classes of phytochemicals screened. Due to their nonpolar nature, these extracts would be expected to contain high levels of lipids, hydrocarbons etc. As our qualitative phytochemical studies did not screen for these compounds, they were not detected and other techniques are required to further examine the nature of these nonpolar components.

\section{Antimicrobial activity.}

To determine the growth inhibitory activity of the D. leichhardtii leaf extracts against the bacterial triggers of the selected autoimmune inflammatory diseases, aliquots $(10 \mu \mathrm{L})$ of each extract were screened in the disc diffusion assay. All D. leichhardtii leaf extracts inhibited P. mirabilis growth (Figure 2). The methanolic and aqueous D. leichhardtii leaf extracts were particularly potent growth inhibitors, each recording zones of inhibition $>12 \mathrm{~mm}$ against both the reference and clinical strains of the bacterium. Indeed, the methanolic D. leichhardtii leaf extract inhibited $P$. mirabilis growth by $21 \pm 1 \mathrm{~mm}$ (reference strain) and $20.6 \pm$ $1.2 \mathrm{~mm}$ (clinical isolate strain). The aqueous extract was also potent, inhibiting the reference and clinical strains by $13.3 \pm 1.5$ and $12.9 \pm 1.2 \mathrm{~mm}$ respectively. This inhibition was particularly noteworthy compared to the inhibition by the ampicillin control $(10 \mu \mathrm{g}$ : inhibition zones of $10.3 \pm$ $0.6 \mathrm{~mm}$ and $10.6 \pm 0.6 \mathrm{~mm}$ against the reference and clinical strains respectively). The ethyl acetate, chloroform and hexane extracts also inhibited the growth of both $P$. mirabilis strains, albeit generally with substantially smaller inhibition zones than were recorded for the methanolic and aqueous extracts.

The D. leichhardtii leaf extracts were similarly potent inhibitors of P. vulgaris (Figure 3). As for P. mirabilis, the methanolic and aqueous extracts were the most potent bacterial growth inhibitors, with zones of inhibition of $18.4 \pm 1.4 \mathrm{~mm}$ and $11.6 \pm 1.2 \mathrm{~mm}$ respectively. Noteably, inhibition by the methanolic extract was substantially more potent than the inhibition by the ampicillin control $(11.8 \pm 0.6 \mathrm{~mm})$. The ethyl acetate, and chloroform extracts also inhibited the growth of $P$. vulgaris, albeit with substantially smaller inhibition zones. The hexane extract was completely devoid of inhibitory activity. As Proteus spp. (particularly P. mirabilis) have been identified as a microbial trigger of rheumatoid arthritis, ${ }^{2-4}$ our results indicate the potential of the D. leichhardtii leaf extracts in preventing and treating that disease.

The D. leichhardtii leaf extracts were also potent inhibitors of K. pneumoniae growth (Figure 4). As reported for Proteus spp. inhibition (Figures 2 and 3), the methanolic extract was the most potent bacterial growth inhibitor, with zones of inhibition of $18 \pm 1 \mathrm{~mm}$ and $18.6 \pm 0.9 \mathrm{~mm}$ against the reference and clinical $K$. pneumoniae strains respectively. The aqueous extract was also a good growth inhibitor with inhibition zones of $16.3 \pm 1.2 \mathrm{~mm}$ and $17 \mathrm{~mm}$ against the reference and clinical $K$. pneumoniae strains respectively. The ethyl acetate, and chloroform extracts induced smaller inhibition zones, although these were still indicative of moderate to good growth inhibitory activity. By comparison, the hexane extract displayed only low inhibitory activity. As K. pneumoniae has been shown to initiate ankylosing spondylitis, ${ }^{2,5-7}$ our results indicate the potential of the D. leichhardtii leaf extracts in the prevention and treatment of that disease.

The methanolic and aqueous $D$. leichhardtii leaf extracts also inhibited A. baylyi growth, albeit with substantially smaller zones of inhibition (approximately 7.5 and $6.3 \mathrm{~mm}$ for the methanolic and aqueous extracts respectively against both reference and clinical strains: Figure 5). Furthermore, none of the D. leichhardtii extracts inhibited the growth of either the reference or clinical $P$. aeruginosa strains (Figure 6). Interestingly, the low level of growth inhibition of $P$. aeruginos $a$ by the ampicillin control $(6.3 \pm 0.3 \mathrm{~mm}$ and $6.4 \pm 0.4 \mathrm{~mm}$ for the reference and clinical strains respectively) indicates that both of these strains were antibiotic resistant. Thus, the D. leichhardtii extracts may still prove to inhibit the growth of other, less resistant $P$. aeruginosa strains and further studies are required to test this. However, based on our results, as all D. leichhardtii extracts had either low efficacy or no activity against these microbial triggers of multiple sclerosis (A. baylyi and P. aeruginosa) ${ }^{8}$ it is unlikely that they would be effective in the prevention and treatment of multiple sclerosis.

The methanolic and aqueous $D$. leichhardtii leaf extracts also inhibited $S$. pyogenes growth, albeit with zones of inhibition indicative of only low potency $(6.8 \pm 0.6$ and $5.8 \pm 0.4 \mathrm{~mm}$ respectively: Figure 7$)$. The ethyl acetate, chloroform and hexane extracts were completely devoid of $S$. pyogenes growth inhibitory activity. S. pyogenes can cause a variety of diseases including streptococcal pharyngitis, impetigo and rheumatic heart disease, ${ }^{10,11}$ depending on which tissue it infects. Thus, our results indicate that the methanolic and aqueous $D$. leichhardtii leaf extracts may have some limited potential in preventing and treating rheumatic heart disease, although with only relatively low efficacy. Isolation studies are required to determine whether isolated anti-S. pyogenes components, which may be in only low abundance in the crude extract, have clinically relevant efficacy in a pure form.

The antimicrobial efficacy was further quantified by determining the MIC values for each extract against the microbial species which were determined to be susceptible. The methanolic and aqueous $D$. leichhardtii 

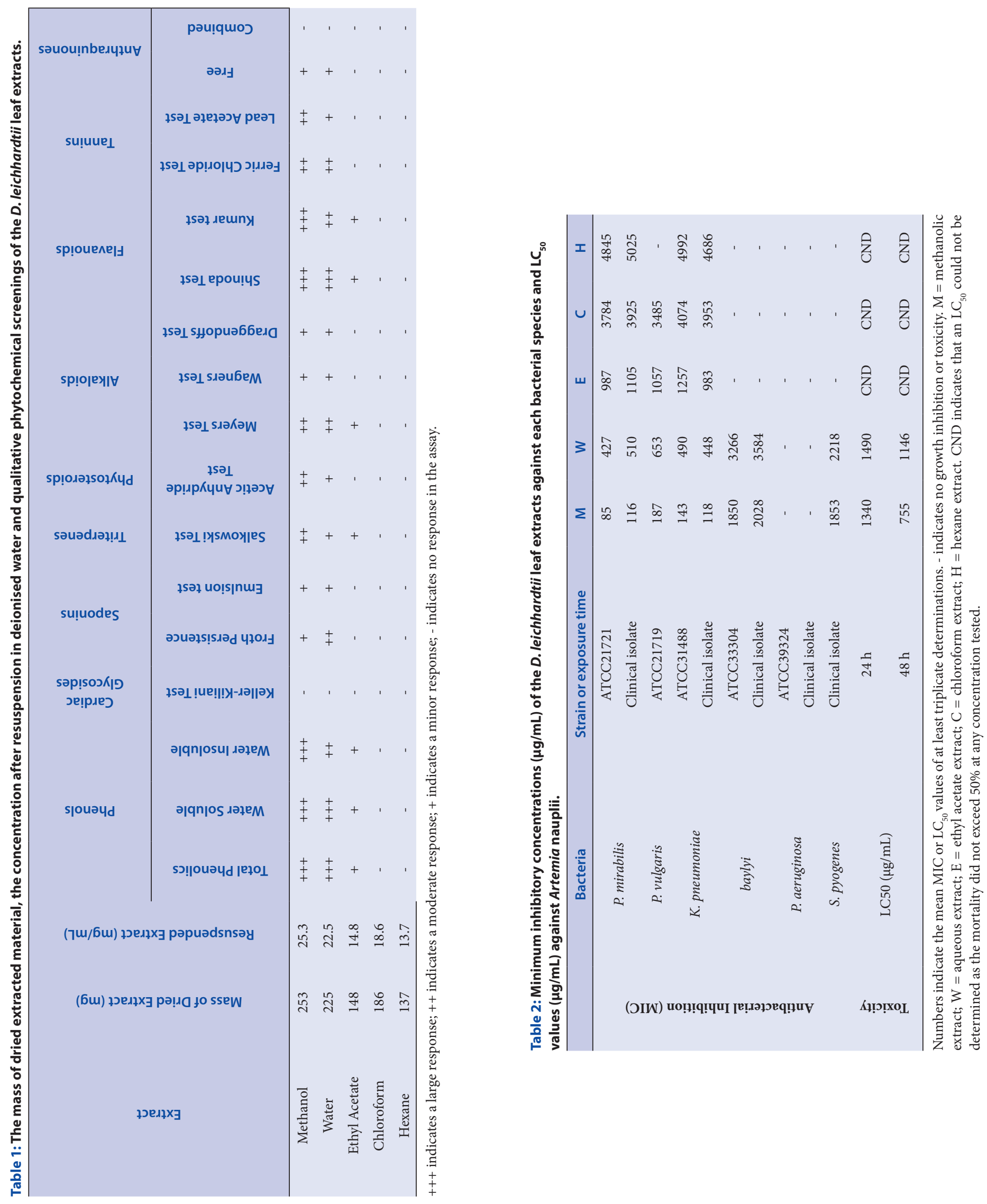

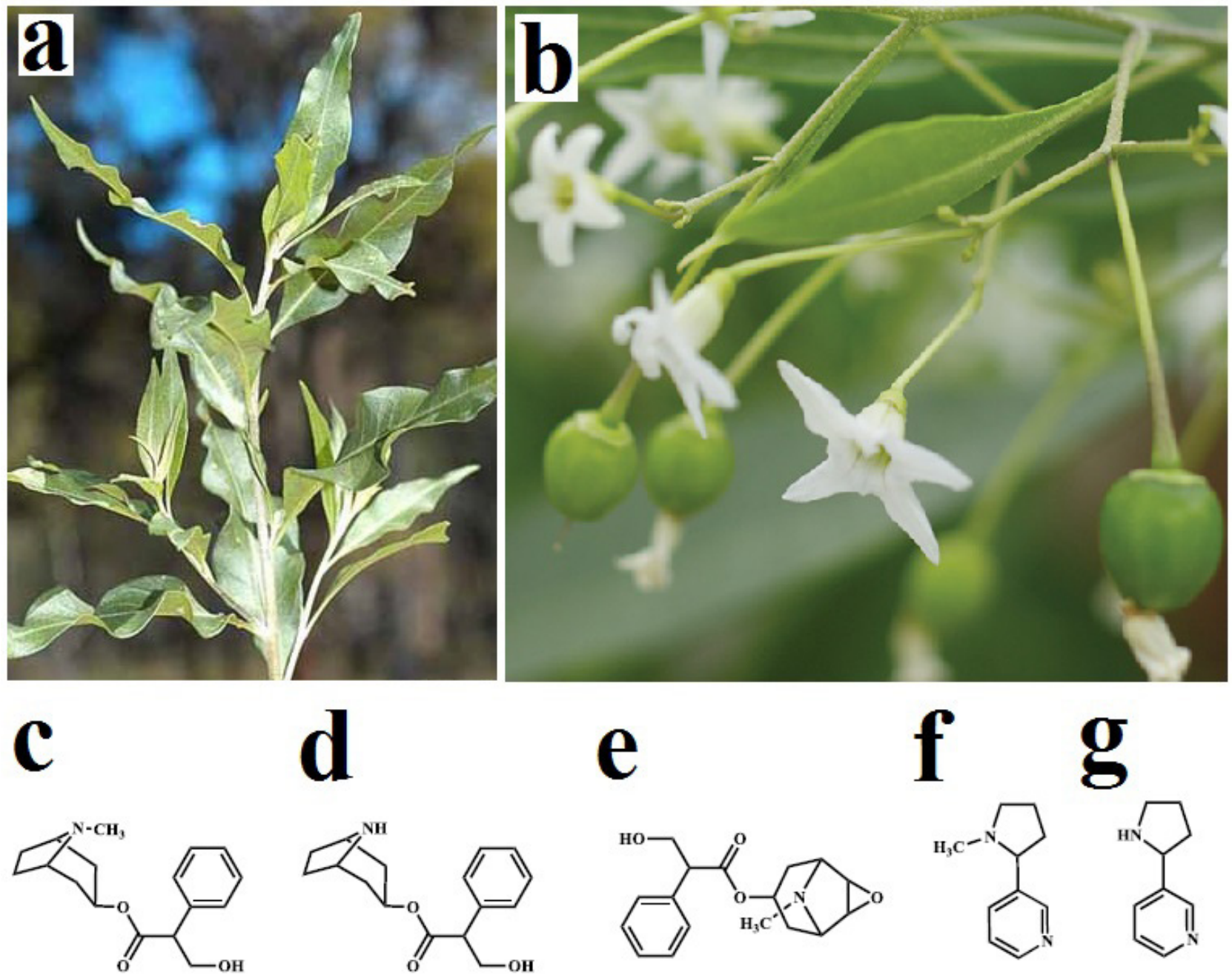

Figure 1: D. leichhardtii (a) leaves, (b) flowers and fruit, as well as the phytochemical compounds (c) hyoscyamine, (d) norhyoscyamine, (e) scopolamine, (f) nicotine and (g) nornicotine.

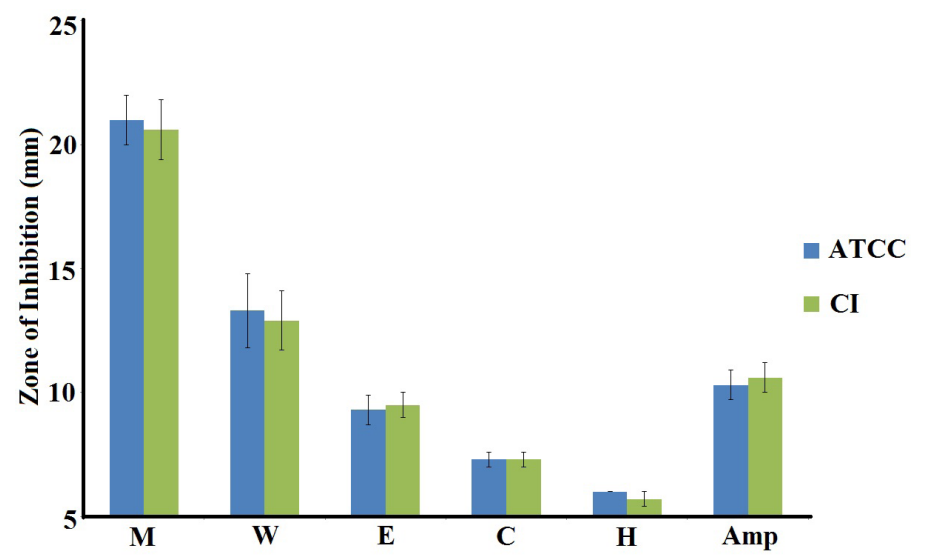

Figure 2: Growth inhibitory activity of $D$. leichhardtii leaf extracts against the reference (ATCC21721) and clinical P. mirabilis strains measured as zones of inhibition $(\mathrm{mm}) \pm$ SEM. Blue bars represent the reference strain (ATCC21721); Green bars represent the clinical isolate strain; $M=$ methanolic extract; $\mathrm{W}=$ aqueous extract; $\mathrm{E}=$ ethyl acetate extract; $\mathrm{C}=$ chloroform extract; $\mathrm{H}=$ hexane extract; Amp = ampicillin $(10 \mu \mathrm{g})$ control; ATCC represents the reference P. mirabilis strain (ATCC21721); Cl represents the clinical isolate strain. All determinations were in triplicate and the results are expressed as mean zones of inhibition $(\mathrm{mm}) \pm \mathrm{SEM}$.

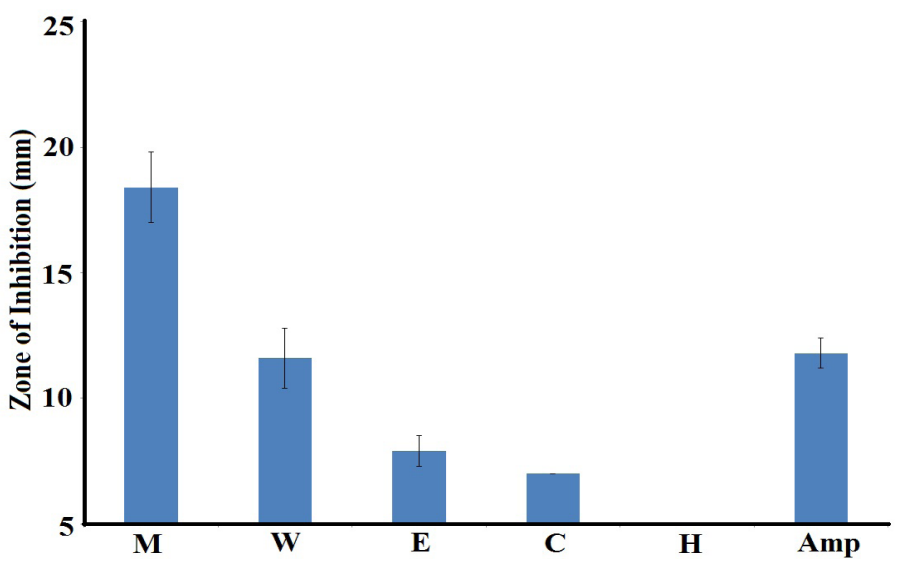

Figure 3: Growth inhibitory activity of $D$. leichhardtii leaf extracts against the reference (ATCC21719) $P$. vulgaris strain as zones of inhibition $(\mathrm{mm}) \pm$ SEM. $\mathrm{M}=$ methanolic extract; $\mathrm{W}=$ aqueous extract; $\mathrm{E}=$ ethyl acetate extract; $\mathrm{C}=$ chloroform extract; $\mathrm{H}=$ hexane extract; $\mathrm{Amp}=$ ampicillin $(10 \mu \mathrm{g})$ control. All determinations were in triplicate and the results are expressed as mean zones of inhibition $(\mathrm{mm}) \pm$ SEM. 


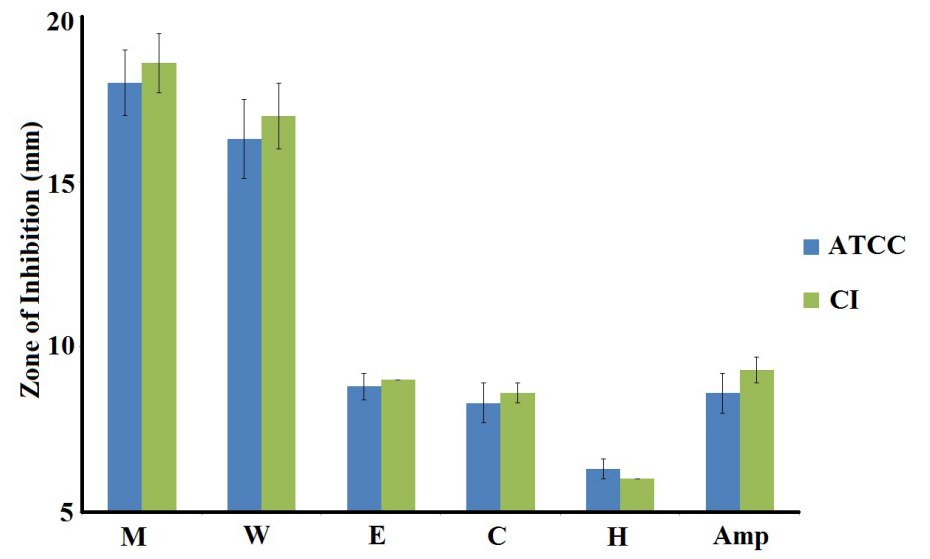

Figure 4: Growth inhibitory activity of the $D$. leichhardtii leaf extracts against the reference (ATCC31488) and clinical K. pneumoniae strains measured as zones of inhibition $(\mathrm{mm}) \pm \mathrm{SEM}$. Blue bars represent the reference strain (ATCC21721); Green bars represent the clinical isolate strain; $M=$ methanolic extract; $W=$ aqueous extract; $E=$ ethyl acetate extract; $C=$ chloroform extract; $\mathrm{H}=$ hexane extract; Amp = ampicillin $(10 \mu \mathrm{g})$ control. All determinations were in triplicate and the results are expressed as mean zones of inhibition $(\mathrm{mm}) \pm \mathrm{SEM}$.

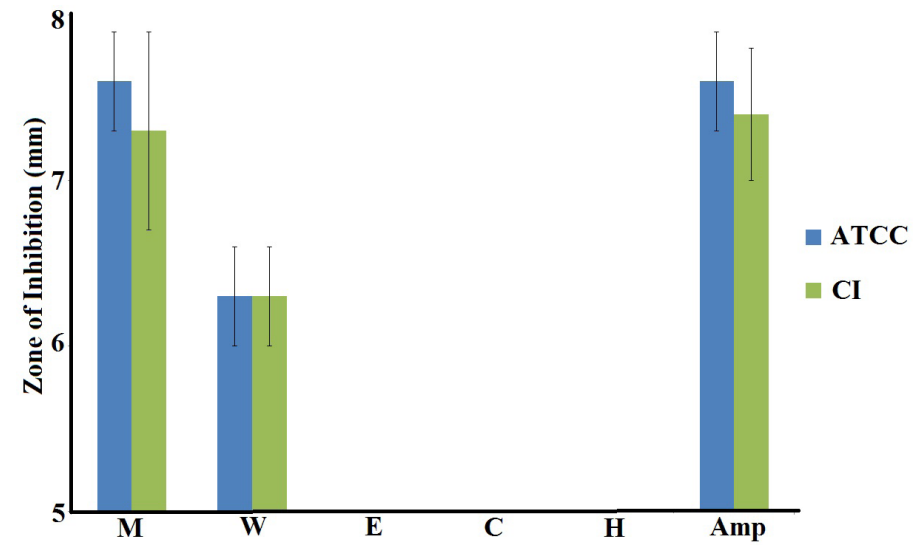

Figure 5: Growth inhibitory activity of the $D$. leichhardtii leaf extracts against reference (ATCC33304) and clinical A. baylyi strains measured as zones of inhibition $(\mathrm{mm}) \pm$ SEM. Blue bars represent the reference strain (ATCC33304); Green bars represent the clinical isolate strain; $\mathrm{M}=$ methanolic extract; $\mathrm{W}=$ aqueous extract; $\mathrm{E}=$ ethyl acetate extract; $\mathrm{C}=$ chloroform extract; $\mathrm{H}=$ hexane extract; Amp = ampicillin $(10 \mu \mathrm{g})$ control. All determinations were in triplicate and the results are expressed as mean zones of inhibition $(\mathrm{mm}) \pm \mathrm{SEM}$.

leaf extracts inhibited all of the bacterial triggers of autoimmune diseases screened except $P$. aeruginosa. Proteus spp. and K. pneumoniae were particularly susceptible to the methanolic and aqueous $D$. leichhardtii leaf extracts, with MIC values generally $<500 \mu \mathrm{g} / \mathrm{mL}$ ( $<5 \mu \mathrm{g}$ infused into the disc). Indeed, an MIC of $85 \mu \mathrm{g} / \mathrm{mL}$ ( $<1 \mu \mathrm{g}$ infused into the disc) was determined for the methanolic extract against the reference $P$. mirabilis strain. These MIC determinations further support the potential of the methanolic and aqueous $D$. leichhardtii leaf extracts for the prevention of rheumatoid arthritis and ankylosing spondylitis in genetically susceptible individuals.

\section{Bacterial growth time course assay.}

The antibacterial activity of the D. leichhardtii leaf extracts was further investigated in P. mirabilis (Figure 8a) and K. pneumoniae (Figure $8 \mathrm{~b}$ )

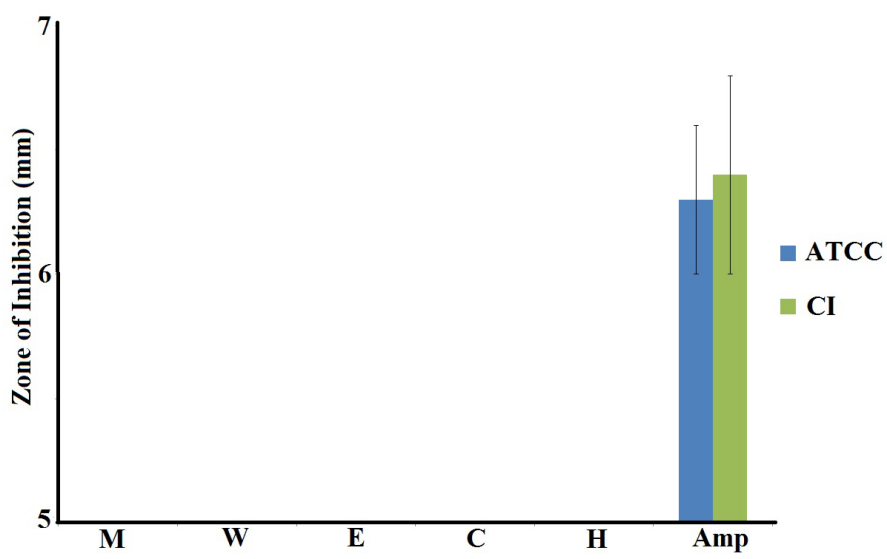

Figure 6: Growth inhibitory activity of the $D$. leichhardtii leaf extracts against reference (ATCC39324) and clinical P. aeruginosa strains measured as zones of inhibition $(\mathrm{mm}) \pm$ SEM. Blue bars represent the reference strain (ATCC39324); Green bars represent the clinical isolate strain; $\mathrm{M}=$ methanolic extract; $\mathrm{W}=$ aqueous extract; $\mathrm{E}=$ ethyl acetate extract; $\mathrm{C}=$ chloroform extract; $\mathrm{H}=$ hexane extract; Amp = ampicillin $(10 \mu \mathrm{g})$ control. All determinations were in triplicate and the results are expressed as mean zones of inhibition $(\mathrm{mm}) \pm \mathrm{SEM}$.

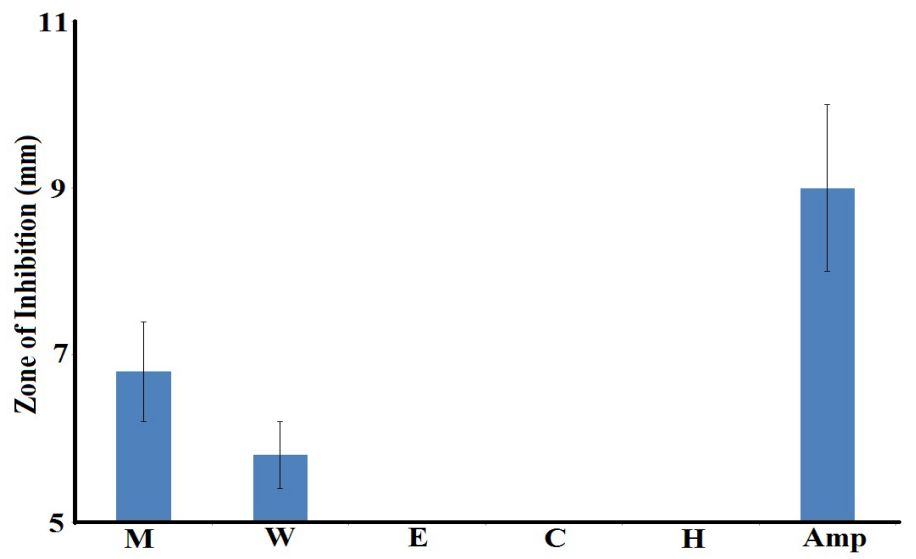

Figure 7: Growth inhibitory activity of the D. leichhardtii leaf extracts against the clinical S. pyogenes strain measured as zones of inhibition $(\mathrm{mm}) \pm \mathrm{SEM}$. $\mathrm{M}=$ methanolic extract; $\mathrm{W}=$ aqueous extract; $\mathrm{E}=$ ethyl acetate extract; $\mathrm{C}=$ chloroform extract; $\mathrm{H}=$ hexane extract; $\mathrm{Amp}=$ ampicillin $(10 \mu \mathrm{g})$ control. All determinations were in triplicate and the results are expressed as mean zones of inhibition $(\mathrm{mm}) \pm \mathrm{SEM}$.

by bacterial growth time course assays in the presence and absence of either the methanolic or aqueous extract. These were the only extracts examined by bacterial growth time course studies as these extracts were generally the most potent inhibitors of bacterial growth. The starting concentration of the extract used in these assays was $1000 \mu \mathrm{g} / \mathrm{mL}$. The methanolic $D$. leichhardtii leaf extract significantly inhibited $P$. mirabilis (Figure $8 \mathrm{a}$ ) and K. pneumoniae (Figure 8b) growth within $1 \mathrm{~h}$, indicating a rapid antimicrobial action. Potent inhibition of $P$. mirabilis (Figure 8a) and K. pneumoniae (Figure 8 b) by the methanolic and aqueous D. leichhardtii leaf extracts was noted, with growth still significantly inhibited by the end of the $6 \mathrm{~h}$ time course study. This may indicate that these extracts have bactericidal activity against $P$. mirabilis and $K$. pneumoniae at the dose tested. Indeed, the turbidity at $6 \mathrm{~h}$ was not greatly increased from the starting turbidity for either bacteria. 


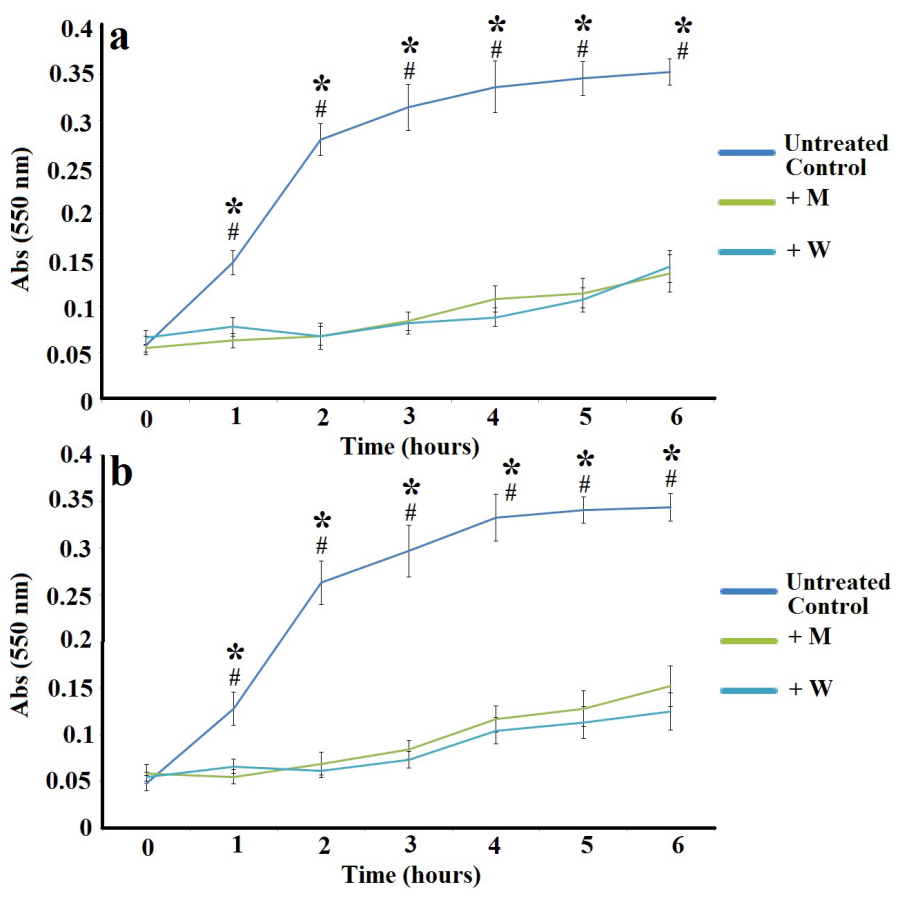

Figure 8: Bacterial growth curves for the methanolic and aqueous D. leichhardtii extracts against (a) P. mirabilis (ATCC21721) and (b) K. pneumoniae (ATCC31488). All bioassays were performed in at least triplicate and are expressed as mean \pm SEM. ${ }^{*}=$ results in the presence of the methanolic extract that are significantly different between the treated and the untreated control growth $(p<0.01) ; \#=$ results in the presence of the aqueous extract that are significantly different between the treated and the untreated control growth $(p<0.01)$.

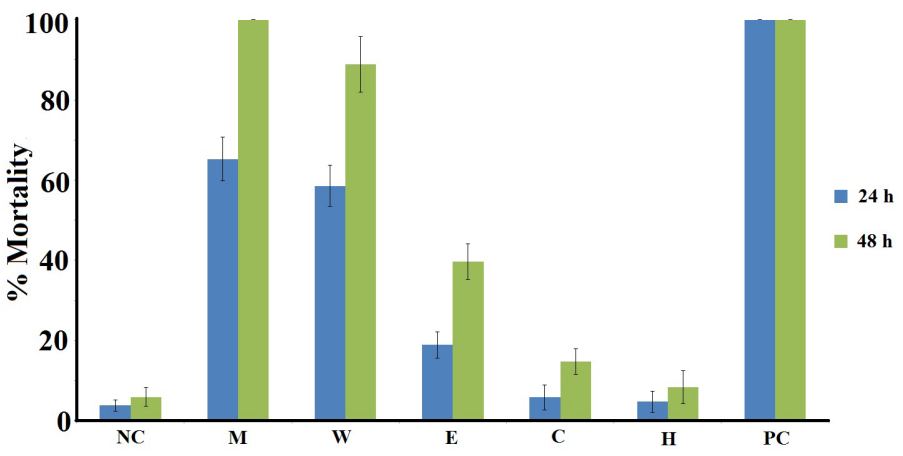

Figure 9: The lethality of the $D$. leichhardtii leaf extracts $(2000 \mu \mathrm{g} / \mathrm{mL})$, potassium dichromate $(1000 \mu \mathrm{g} / \mathrm{mL})$ and a seawater control. Blue bars represent the $\%$ mortality following $24 \mathrm{~h}$ exposure; green bars represent the $\%$ mortality following $48 \mathrm{~h}$ exposure; $\mathrm{M}=$ methanolic extract; $\mathrm{W}=$ aqueous extract; $\mathrm{E}=$ ethyl acetate extract; $\mathrm{C}=$ chloroform extract; $\mathrm{H}=$ hexane extract; $\mathrm{NC}=$ negative (seawater) control; $\mathrm{PC}=$ positive control $(1000 \mu \mathrm{g} / \mathrm{mL}$ potassium dichromate). All bioassays were performed in at least triplicate and are expressed as mean \pm SEM.

\section{Quantification of toxicity.}

The toxicity of the $D$. leichhardtii leaf extracts was initially tested in the Artemia franciscana nauplii bioassay at a concentration of $2000 \mu \mathrm{g} / \mathrm{mL}$ (Figure 9). The methanolic and aqueous extracts induced $>50 \%$ mortality at $24 \mathrm{~h}$ at $2000 \mu \mathrm{g} / \mathrm{mL}$ in the screening study and thus were deemed to be toxic. All of the other extracts induced low levels of mortality at $24 \mathrm{~h}$, similar to the \% mortality seen for the seawater control. By $48 \mathrm{~h}$, the mortality induction had increased for all of the D. leichhardtii leaf extracts. However, as the methanolic and aqueous extracts were still the only extracts which induced $>50 \%$ toxicity at $48 \mathrm{~h}$, all other extracts were deemed to be nontoxic. In contrast, the potassium dichromate positive control induced mortality within $4 \mathrm{~h}$ (results not shown), with $100 \%$ mortality induction seen by $24 \mathrm{~h}$.

To further quantify the effect of toxin concentration on the induction of mortality, the extracts were serially diluted in artificial seawater to test across a range of concentrations in the Artemia nauplii bioassay (Table 2). For comparison, serial dilutions of potassium dichromate were also tested. All extracts were determined to be nontoxic, with $\mathrm{LC}_{50}$ values $>1000 \mu \mathrm{g} / \mathrm{mL}$ following $24 \mathrm{~h}$ exposure. Extracts with an $\mathrm{LC}_{50}>1000$ $\mu \mathrm{g} / \mathrm{mL}$ towards Artemia nauplii have previously been defined as being nontoxic..$^{29}$

\section{DISCUSSION}

Plant derived remedies are becoming increasingly sought after in the treatment of a myriad of diseases and disorders due both to their perception of greater safety than many synthetic drugs, and the failure of current drug regimens to effectively treat many diseases. This is especially true for chronic disorders such as the autoimmune inflammatory diseases. The current treatments which utilise disease modifying antirheumatic drugs (DMARDs) to alleviate the symptoms of these diseases and/or alter the disease progression are not entirely effective and have been associated with numerous adverse effects. ${ }^{1}$ Furthermore, many of the current treatments are aimed at treating the symptoms without addressing the underlying causes and pathogenic mechanisms. A better understanding of the mechanisms for initiation and progression of the autoimmune inflammatory diseases is important for developing new drugs to target specific processes and thus more effectively treat autoimmune inflammatory diseases. The studies reported here examined the ability of $D$. leichhardtii leaf extracts to block microbial triggers of 4 autoimmune inflammatory disorders (Proteus spp.: rheumatoid arthritis; K. pneumonia: ankylosing spondylitis; A. baylyi and P. aeruginosa: multiple sclerosis; $S$. pyogenes: rheumatic heart disease). Several extracts were identified as potent inhibitors of these bacteria. Particularly noteworthy, the methanolic and aqueous extracts were identified as potent inhibitors of the growth of the bacterial triggers of rheumatoid arthritis and ankylosing spondylitis, and were generally more potent growth inhibitors than were the ampicillin antibacterial controls.

Whilst a detailed investigation of the phytochemistry of the D. leichhardtii leaf extracts was beyond the scope of our study, qualitative screening studies were used to determine the classes of compounds present. These studies indicated that polyphenolics, flavonoids, tannins and alkaloids were present in the most potent $D$. leichhardtii leaf extracts. Studies have linked polyphenolic compounds and alkaloids with anti-bacterial activity in different plant species ${ }^{30}$ and thus these compounds may be responsible (at least in part) for the bacterial growth inhibitory activities reported here. Interestingly, several of these phytochemical classes have also been reported to suppress NF- $\kappa B$ signaling. ${ }^{30}$ Thus, these extracts may have pleuripotent effects against autoimmune inflammatory diseases, with therapeutic properties against the trigger events as well as the later inflammatory responses. Further phytochemical evaluation studies and bioactivity driven isolation of the active components is required to further evaluate the mechanism of bacterial growth inhibition.

Previous studies have also confirmed the presence of significant alkaloid components in Duboisia spp. extracts. In particular, the tropane alkaloids scopolamine, hyoscyamine and norhyoscyamine, as well as the pyrrolidine alkaloids nicotine and nornicotine have been detected in relatively high levels in many Duboisia spp. (although the relative levels differ between species/locations). ${ }^{15}$ The tropane alkaloids scopolamine, hyoscyamine and norhyoscyamine have been particularly well studied 
as they have potent psychoactive properties via acetylcholine receptor antagonism. Thus, they are indicated as sedatives and hypnotics (or stimulants at low doses). ${ }^{15}$ The pyrrolidine alkaloids nicotine and nornicotine also act via the acetylcholine receptor, although they are agonists and function as stimulants. ${ }^{15}$ Interestingly, potent antibacterial activity has been reported for scopolamine (MIC values as low as $2 \mu \mathrm{g} / \mathrm{mL}$ against multiple bacteria). ${ }^{16}$ Similarly, nicotine inhibits the growth of E. coli, P. aeruginosa and $S$. faecalis. ${ }^{17}$ However, it is noteworthy that all of these alkaloids have been reported to have substantial toxicity, which may limit the usable safe doses. Thus, D. leichhardtii leaf extracts and essential oils should be used with caution.

Although our study demonstrated the potential of the D. leichhardtii leaf extracts to prevent and treat autoimmune disease, much more work is required. This study has only tested these extracts against microbial triggers of 4 autoimmune diseases (rheumatoid arthritis, ankylosing spondylitis, multiple sclerosis and rheumatic heart disease). The microbial triggers for several other autoimmune inflammatory disorders are also known. Borrelia burgdorferi is linked with Lyme disease ${ }^{9}$ and Mycoplasma pneumoniae is associated with several demyelinating diseases. ${ }^{12}$ It would be interesting to extend our studies to also screen for the ability of the extracts to block these microbial triggers of autoimmune diseases.

Despite the presence of the tropane and pyrrolidine alkaloids in Duboisia spp. extracts, ${ }^{15}$ our studies determined that all of the D. leichhardtii leaf extracts were nontoxic towards Artemia franciscana nauplii, with $\mathrm{LC}_{50}$ values $>1000 \mu \mathrm{g} / \mathrm{mL}$. Extracts with $\mathrm{LC}_{50}$ values $>1000 \mu \mathrm{g} / \mathrm{mL}$ towards Artemia nauplii are defined as being nontoxic. ${ }^{29}$ Whilst our preliminary toxicity studies indicate that these extracts may be safe for therapeutic use, studies using human cell lines are required to further evaluate the safety of these extracts. Furthermore, this study only screened for toxicity defined as mortality. Due to the intoxicating properties of the Duboisia spp. alkaloids, it may also be necessary to test the extracts for other markers of toxicity. Whilst these studies have demonstrated the potential of the D. leichhardtii leaf extracts in the development of future antibiotic chemotherapeutics for the prevention and treatment of autoimmune diseases (particularly rheumatoid arthritis and ankylosing spondylitis), more work is required to isolate the inhibitory components and determine the mechanism of inhibition.

\section{CONCLUSIONS}

The results of this study demonstrate the potential of the D. leichhardtii leaf extracts as inhibitors of the growth of bacterial species associated with the onset of some autoimmune inflammatory diseases (particularly rheumatoid arthritis and ankylosing spondylitis). Furthermore, their lack of toxicity indicates than they are safe for internal as well as topical treatment.

\section{ACKNOWLEDGEMENTS}

The authors are grateful to Philip Cameron for identifying and providing the plant material used in this study. We are also grateful to Michelle Mendell and Jane Gifkins for the gift of the clinical isolate bacterial strains. Financial support for this work was provided by the Environmental Futures Research Institute and the School of Natural Sciences, Griffith University, Australia.

\section{CONFLICTS OF INTEREST}

The authors report no conflicts of interest.

\section{ABBREVIATIONS}

DMSO: Dimethyl sulfoxide

$\mathrm{LC}_{50}$ : The concentration required to achieve $50 \%$ mortality

MIC: minimum inhibitory concentration

\section{REFERENCES}

1. Alataha D, KapralT, Smolen JS. Toxicity profiles of traditional disease modifying antirheumatic drugs for rheumatoid arthritis. Ann Rheum Dis. 2003;62(5):482-6.

2. Ebringer A, Rashid T. Rheumatoid arthritis is an autoimmune disease triggered by Proteus urinary tract infection. Clin Develop Immunology Research. 2006;13(1):41-8.

3. Ebringer A, Cunningham P, Ahmadi K, et al. Sequence similarity between HLA-DR1 and DR4 subtypes associated with rheumatoid arthritis and Proteus/ Serratia membrane haemolysins. Ann Rheum Dis. 1992;51:1245-1246.

4. Cock I, van Vuuren SF. Anti-Proteus activity of some South African medicinal plants: their potential for the prevention of rheumatoid arthritis. Inflammo pharmacology. 2014;22(1):23-36. DOI:10.1007/ s10787-013-0179-3.

5. Schwimmbeck PL, Yu DTY, Old stone MBA. Auto-antibodies to HLA-B27 in the sera of HLA-B27 patients with ankylosing spondylitis and Reiter's syndrome: molecular mimicry with Klebsiella pneumoniae as a potential mechanism of autoimmune disease. J Exp Med. 1987;166(1):173-181.

6. Ebringer A, Rashid T, Wilson $\mathrm{C}$ et al. Ankylosing spondylitis as an auto-immune disease linked to intestinal Klebsiella infection: prospects for a new therapeutic approach. Curr Rheum Rev. 2006;2:55-68.

7. Fielder M, Pirt SJ, Tarpey I et al. Molecular mimicry and ankylosing spondylitis: possible role of a novel sequence in pullulanase of Klebsiella pneumoniae. FEBS Letters. 1995;369(2-3):243-8.

8. Ebringer A, Hughes L, RashidT, et al. Acinetobacter immune response in multiple sclerosis. Etiopathogenetic role and its possible use as a diagnostic marker. JAMA Neurol. 2005;62(1):33-6.

9. Beermann C, Wunderli-Allenspach H, Groscurth $\mathrm{P}$, et al. Lipoproteins from Borrelia burgdorferiapplied in liposomes and presented to dendritic cells induce CD8+ T-lymphocytes in vitro. Cellular Immunology. 2000;201 (2):124-131.

10. Lee CJ, Wright MH, Arnold MSJ, et al. Inhibition of Streptococcus pyogenes growth by native Australian plants: New approaches towards the management of impetigo, pharyngitis and rheumatic heart disease. Pharmacognosy Communications. 2016;6(3):164-73. DOI: 10.5530/pc.2016.3.6.

11. Wright $\mathrm{MH}$, Arnold MSJ, Lee $\mathrm{CJ}$, et al. Qualitative phytochemical analysis and antibacterial activity evaluation of Indian Terminalia spp. against the pharyngitis causing pathogen Streptococcus pyogenes. Pharmacognosy Communications. 2016;6(2):82-92. DOI: 10.5530/pc.2016.2.6

12. Kollef $\mathrm{MH}$, West $\mathrm{S}$, Davis $\mathrm{DR}$, et al. Central and peripheral nervous system demyelination after infection with Mycoplasma pneumoniae. Evidence of an autoimmune process. Southern Med J. 1991;84(10):1255-8.

13. Cock IE. Medicinal and aromatic plants - Australia. In Ethnopharmacology, Encyclopedia of Life Support Systems (EOLSS), 2011. Developed under the auspices of UNESCO. Oxford, UK: EOLSS Publishers; 2011. Available from: http://www.eolss.net. Accessed 1 April 2013.

14. Lassak EV, McCarthy T. Australian medicinal plants. New Holland Publishers 2011; Australia.

15. Cock IE, Cheesman MJ. Oceania: Antidepressant medicinal plants. In Herbal Medicine in Depression. Springer International Publishing 2016; New York USA: 483-527. DOI: 10.1007/978-3-319-14021-6_10.

16. Ozcelik B, Kartal M, Orhan I. Cytotoxicity, antiviral and antimicrobial activities of alkaloids, flavonoids, and phenolic acids. Pharmceutical Biology. 2011;49(4): 396-402.

17. Zaidi Ml, Wattoo FH, Wattoo MHS, et al. Antibacterial activities of nicotine and its zinc complex. African Journal of Microbiology Research. 2012;6(24):5134-7.

18. Boyer H, Cock IE. Evaluation of the potential of Macademia integriflora extracts as antibacterial food agents. Pharmacognosy Communications. 2013;3(3):53-62. DOI: $10.5530 / p c .2013 .3 .10$.

19. Courtney R, Sirdaarta J, Matthews B, et al. Tannin components and inhibitory activity of Kakadu plum leaf extracts against microbial triggers of autoimmune inflammatory diseases. Pharmacognosy Journal. 2015;7(1):18-31. DOI: 10.5530/pj.2015.7.2.

20. Hart C, Ilanko P, Sirdaarta J, et al. Tasmannia stipitata as a functional food/natural preservative: Antimicrobial activity and toxicity. Pharmacognosy Communications 2014;4(4):33-47. DOI: 10.5530/pc.2014.4.4.

21. Mpala L, Chikowe G, Cock IE. No evidence of antiseptic properties and low toxicity of selected Aloe species. Journal of Pharmaceutical Negative Results. 2010;1(1):10-16. DOI: 10.4103/0976-9234.68869. 
22. Sirdaarda J, Matthews B, White A, et al. GC-MS and LC-MS analysis of Kakadu plum fruit extracts displaying inhibitory activity against microbial triggers of multiple sclerosis. Pharmacognosy Communications. 2015;5(2):100-15. DOI: 10.5530/pc.2015.2.2

23. Kalt FR, Cock IE. Gas chromatography-mass spectroscopy analysis of bioactive Petalostigma extracts: Toxicity, antibacterial and antiviral activities. Pharmacognosy Magazine. 2014;10(Suppl 1):S37-49. DOI: 10.4103/0973-1296.127338.

24. Vesoul J, Cock IE. The potential of Bunya nut as an antibacterial food agent. Pharmacognosy Communications. 2012;2(1):72-9. DOI: 10.5530/pc.2012.1.13.

25. Arkhipov A, Sirdaarta J, Rayan $P$, et al. An examination of the antibacterial, antifungal, anti-Giardial and anticancer properties of Kigelia africana fruit extracts. Pharmacognosy Communications. 2014;4(3):62-76. DOI: 10.5530/pc.2014.3.7.

26. Cock IE. Antimicrobial activity of Acacia aulacocarpa and Acacia complanta methanolic extracts. Pharmacognosy Communications. 2012;2(1):66-71. DOI: 10.5530/pc.2012.1.12.
27. Cock IE. Assessment of the toxicity of selected Australian native plant extracts using the Artemia franciscana nauplii bioassay. Internet Journal of Toxicology. 2008;5:2.

28. Ruebhart DR, Wikramasinghe WA, Cock IE. Protective efficacy of the antioxidants vitamin E and Trolox against Microcystis aeruginosa and microcystin-LR in Artemia franciscana nauplii. Journal of Toxicology and Environmental Health Part A. 2009;72(24):1567-75.

29. Cock IE, Ruebhart DR. Comparison of the brine shrimp nauplii bioassay and the ToxScreen-II test for the detection of toxicity associated with Aloe vera (Aloe barbadensis Miller) leaf extract. Pharmacognosy Research. 2009;1(2):98-101.

30. Cock IE. The phytochemistry and chemotherapeutic potential of Tasmannia lanceolata (Tasmanian pepper): A review. Pharmacognosy Communications. 2013:3(4):13-25. DOI: 10.5530/pc.2013.4.3.

Cite this article : Cock IE. Duboisia leichhardtii (F.Muell.) Extracts Inhibit The Growth of Bacterial Triggers of Selected Autoimmune Inflammatory Diseases. Pharmacognosy Journal. 2016;8(6):542-550.

PICTORIAL ABSTRACT

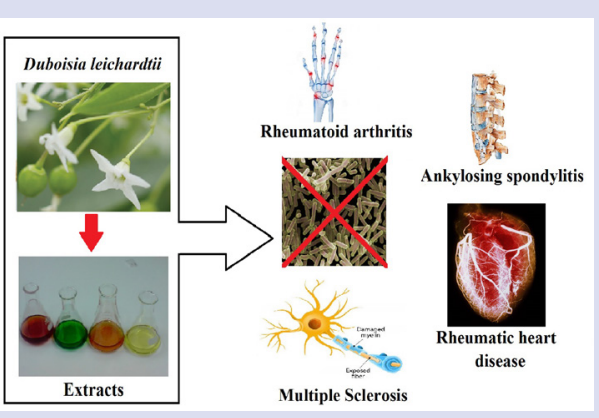

\section{SUMMARY}

- D. leichhardtiileaf extracts were potent inhibitors of the bacterial triggers of rheumatoid arthritis (Proteus spp.) and ankylosing spondylitis (K. pneumoniae).

- The methanolic extract was a particularly potent inhibitor of Proteus spp. growth, with MICs $<200 \mu \mathrm{g} / \mathrm{mL}$ against all strains.

- The methanolic extract was also a good inhibitor of $K$. pneumoniae growth with MICs $<150 \mu \mathrm{g} / \mathrm{mL}$.

- The aqueous and ethyl acetate extracts were also potent bacterial growth inhibitors, albeit with slightly higher MIC values.

- All D. leichhardtii leaf extracts were nontoxic.

\section{ABOUT AUTHORS}

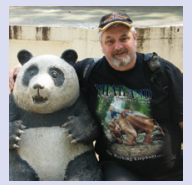

Dr lan Cock leads a research team in the Environmental Futures Research Institute and the School of Natural Sciences at Griffith University, Australia. His research involves bioactivity and phytochemical studies into a variety of plant species of both Australian and international origin, including Aloe vera, South Asian and South American tropical fruits, as well as Australia plants including Scaevola spinescens, Pittosporum phylliraeoides, Terminalia ferdinandiana (Kakadu plum), Australian Acacias, Syzygiums, Petalostigmas and Xanthorrhoea johnsonii (grass trees). This range of projects has resulted in nearly 200 publications in a variety of peer reviewed journals. 